\title{
Multispectral imaging of acute wound tissue oxygenation
}

\author{
Audrey Huong*, Sheena Philimon and Xavier Ngu \\ Department of Electronic Engineering \\ Faculty of Electrical and Electronic Engineering \\ University Tun Hussein Onn Malaysia \\ Batu Pahat 86400, Johor, Malaysia \\ *audrey@uthm.edu.my
}

Received 27 June 2016

Accepted 14 December 2016

Published 8 February 2017

\begin{abstract}
This paper investigates the appropriate range of values for the transcutaneous blood oxygen saturation $\left(\mathrm{S}_{\mathrm{t}} \mathrm{O}_{2}\right)$ of granulating tissues and the surrounding tissue that can ensure timely wound recovery. This work has used a multispectral imaging system to collect wound images at wavelengths ranging between $520 \mathrm{~nm}$ and $600 \mathrm{~nm}$ with a resolution of $10 \mathrm{~nm}$. As part of this research, a pilot study was conducted on three injured individuals with superficial wounds of different wound ages at different skin locations. The $\mathrm{S}_{t} \mathrm{O}_{2}$ value predicted for the examined wounds using the Extended Modified Lambert-Beer model revealed a mean $\mathrm{S}_{\mathrm{t}} \mathrm{O}_{2}$ of $61 \pm 10.3 \%$ compared to $41.6 \pm 6.2 \%$ at the surrounding tissues, and $50.1 \pm 1.53 \%$ for control sites. These preliminary results contribute to the existing knowledge on the possible range and variation of wound bed $\mathrm{S}_{\mathrm{t}} \mathrm{O}_{2}$ that are to be used as indicators of the functioning of the vasomotion system and wound health. This study has concluded that a high $\mathrm{S}_{\mathrm{t}} \mathrm{O}_{2}$ of approximately $60 \%$ and a large fluctuation in this value should precede a good progression in wound healing.
\end{abstract}

Keywords: Multispectral imaging; wound healing; transcutaneous blood oxygen saturation; extended modified Lambert-Beer.

\section{Introduction}

Wound tissue oxygen consumption is a much-discussed subject in studies involving post-operative evaluation and skin grafting procedures. Oxygen is one of the key determinants in healing outcomes, wherein by combining it with sufficient nutrients in the inter-microcirculatory environment a proper wound healing should be ensured. It was previously demonstrated that poor local tissue oxygenation would indicate a poor healing outcome or compromised skin grafts. ${ }^{1}$ The wound healing process can be categorized into three phases: tissue inflammation, which starts upon injury and normally lasts between 3 and 4 days, followed by the proliferative

${ }^{*}$ Corresponding author.

This is an Open Access article published by World Scientific Publishing Company. It is distributed under the terms of the Creative Commons Attribution 4.0 (CC-BY) License. Further distribution of this work is permitted, provided the original work is properly cited. 
stage that involves the development of new blood vessels, which may take up to weeks, and lastly the tissue remodeling phase that produces the scarring of tissue. ${ }^{2}$ Previous literatures ${ }^{3,4}$ have revealed that the microcirculation system of the wound and its surrounding tissues shows an acute hypoxic condition from the constriction and rechanneling of blood vessels away from this site during the onset of tissue injury to mitigate bleeding; the recovery of wound tissue oxygenation through angiogenesis following this step is essential for physiological healing. In chronic wounds, such as diabetic wounds, tissue oxygenation fails to be restored, thereby impairing the healing processes.

The delivery of oxygen and nutrients is dependent on blood supply to the tissue. The latter is subjected to the performance of pulmonary gas exchange, blood hemoglobin level, perfusion and cardiac output. Other factors that interrupt progressive wound healing include age, smoking and presence of infection. To provide an understanding of the mechanisms of wound healing, some works focus on the investigation of differences in the transcutaneous oxygen partial pressure at wound sites compared to that in normal, healthy skin sites, ${ }^{5}$ while others focus on changes in the transcutaneous oxygen saturated blood during the start of skin integrity impairment (tissue inflammation phase $)^{6}$ and as wound healing progressed. ${ }^{7}$ In reality, there is an overlap in wound healing phases, and an individual wound may be in different phases at a time. $^{8}$ This is complicated by the diversity of wounds such as heavily exuding wounds and eschar.

The common technique for wound healing assessment is based on visual evaluation due to its real time and cost effective attributes. The state of the art in in vivo techniques that use wound oxygenation level as an indirect tool to assess wound healing include the use of polarographic probe or needle electrode on subcutaneous wound tissues for surface measurement of partial oxygen $\left(\mathrm{PO}_{2}\right)$ level, ${ }^{9}$ and the use of luminescence lifetime imaging (LII) ${ }^{10}$ for two dimensional visualization of $\mathrm{PO}_{2}$ based on the quenching of phosphorescence. Even though photoacoustic imaging is a noninvasive technique to provide blood vessel mapping, it requires a long operation time. Multimodal optical imaging, which combines optical microangiography and laser speckle imaging technique, has emerged as a new technique to acquire a microvascular map (tissue blood perfusion and oxygenation). ${ }^{3}$ Wang et al. ${ }^{3}$ has performed the corresponding technique on the ears of mice to the monitor wound healing process; the workers have observed a decrease in hemodynamic activities following the injury. This is prior to an increase in the blood flow and changes in oxygenation value during the revasculation. In addition, other related studies have recently demonstrated the feasibility of using hyperspectral imaging technique to monitor blood oxygen saturation of different wound samples. ${ }^{1}$ The use of this technique is, however, time consuming in terms of data collection and analysis. This study systematically reports the $\mathrm{S}_{\mathrm{t}} \mathrm{O}_{2}$ range of wound tissue of several wound types, and compares that with $\mathrm{S}_{\mathrm{t}} \mathrm{O}_{2}$ of surrounding healthy tissue.

\section{Materials and Methods}

\subsection{Experiment system and procedures}

The in-house assembled multispectral imaging system is shown in Fig. 1. This work used a white light emitting diode (XQ-E from Cree) as the light source owing to its high intensity and the good stability in its output. A mini monochromator (part No. 78026 from Newport) was used to spectrally resolve the illuminating white light into specific wavelengths by its built-in diffraction grating. This study selected wavelengths in the range of $520-600 \mathrm{~nm}$ with a sampling size of $10 \mathrm{~nm}$ to illuminate the selected skin region. The resolution of the monochromator system's light output in this wavelength range was approximately $2-3 \mathrm{~nm}$ with the use of an exit slit with a size of $30 \mu \mathrm{m} \times 4 \mathrm{~mm}$. The experiment was

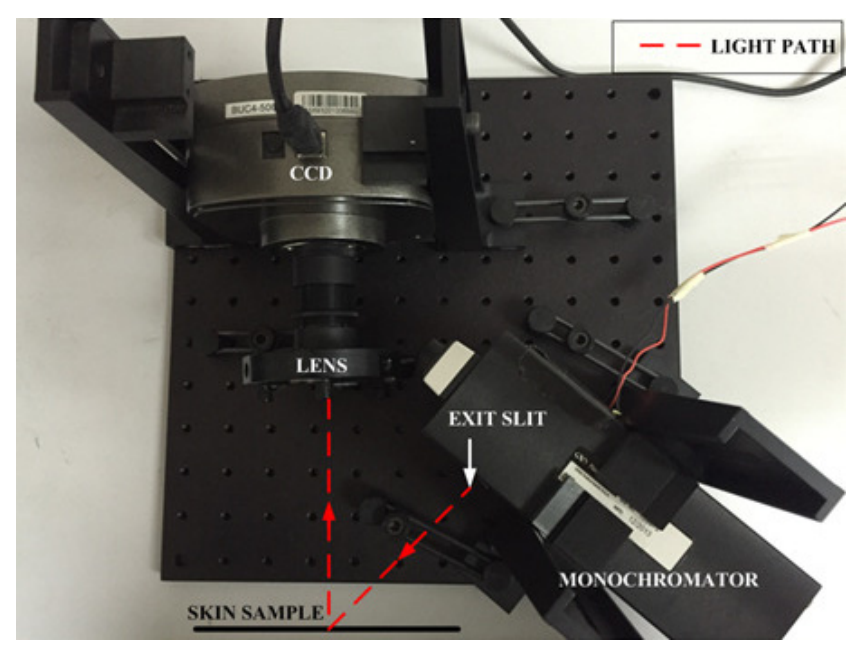

Fig. 1. Multispectral imaging system. 
performed in the reflection mode; thus, the monochromatic system was placed at a distance of $130 \mathrm{~mm}$ and an angle of approximately $45^{\circ}$ from the skin site to reduce glare.

The detection system consisted of a plano convex lens with a diameter of $\phi=12.7 \mathrm{~mm}$ and focal length of $50.22 \mathrm{~mm}$ to focus the light reflected from the targeted site onto a charge coupled imager (CCD) (BUC4 - 500C from BestScope). This camera produced a $2580 \times 1944$ pixels image with a pixel size of $3.4 \mu \mathrm{m} \times 3.4 \mu \mathrm{m}$. The field of view of the detection system was given as $15 \mathrm{~mm} \times 18.75 \mathrm{~mm}$. The optical lens was placed at a normal angle to the skin surface in front of the imager; the latter was located $170 \mathrm{~mm}$ from the skin. The integration time of CCD was set to $5 \mathrm{~s}$ to increase the signal-to-noise performance of the signals.

This study recruited three nonsmoking patients aged between 21 and 26 years, all of whom were of Asian origin for investigations of wound tissue oxygenation. These volunteers were home students from the University Tun Hussein Onn (UTHM) and were among the patients receiving treatment at the University Health Centre, UTHM during the data collection period. The volunteers were briefed on the experiment procedures and gave their informed consent before the experiment. They were required to declare their long term illness, if any. Those with diabetes, severe burns, AIDS, cancer and heart disease, who are at a greater risk of developing chronic wound, were excluded from this study. The participants of this study were identified as the group with clean, acute wounds at different parts of the body. These wounds were at least three days old but not more than two weeks old, and the cessation of bleeding could be observed. The participants were required to place their injured parts on a makeshift scaffold and remained still throughout the experiments to prevent artifacts. Spectroscopy data of the targeted sites were collected after the wound had been cleaned but prior to changing the wound dressing. These wounds were assessed and categorized by medical professionals as those that had healed timely and properly during their last follow-up visit when dressing was no longer required.

To compare the tissue oxygen level of a wound and its proximities with that of healthy, normal skin sites, this study recruited eight other individuals aged between 20 and 26 years. These individuals were nonsmokers and were identified as those who had complied with the above mentioned health criteria. Spectroscopic measurement was performed on their central forehead, posterior forearm, thenar region of the palm and the proximal part of the ankle, which were selected as the control sites.

This work used light attenuation data in the estimation of tissue oxygenation. This was given by the logarithm of the ratio of white reference from the spectralon (part no. AS-01158-060 from Labsphere, Inc) and the wound reflectance data. Both of these were mathematically subtracted for dark noise before the calculation of the required attenuation.

\subsection{Extended modified Lambert-Beer model and iterative fitting procedure}

This work used the Extended Modified LambertBeer model shown in Eq. (1) for the estimation of the wound tissue oxygen saturation level. This light attenuation model was the extended version of the Modified Lambert Beer model first proposed by Huong and $\mathrm{Ngu}^{11}$ for the prediction of oxyhemoglobin and carboxyhemoglobin using data simulated by the Monte Carlo model. The accuracy of the tissue oxygen saturation value predicted by this model was evaluated using different experimental methods. ${ }^{12}$ The value was also compared with that presented in the literature.

$$
A(\lambda)=G_{0}+\mu_{\mathrm{a}} d_{0}+G_{1} \lambda+\lambda \exp \left(-\mu_{\mathrm{a}} d_{1}\right) .
$$

This version of the model provides a rough approximation of the skin light attenuation by including additional intertwined effects of light absorption and scattering on the total light attenuation of the epidermis and dermis layer in the third and fourth term of Eq. (1), respectively. The light absorption, $\mu_{\mathrm{a}}$, in Eq. (1) can be expressed as a function of the extinction coefficient of oxyhemoglobin $\left(\varepsilon_{\mathrm{HbO}_{2}}\right)$ and deoxyhemoglobin $\left(\varepsilon_{\mathrm{Hb}}\right)$ as follows:

$$
\mu_{\mathrm{a}}(\lambda)=\varepsilon_{\mathrm{HbO}_{2}} C_{\mathrm{HbO}_{2}}+\varepsilon_{\mathrm{Hb}} C_{\mathrm{Hb}},
$$

where $C_{\mathrm{HbO}_{2}}$ and $C_{\mathrm{Hb}}$ are the concentration of oxyhemoglobin and deoxyhemoglobin, respectively. Equation (2) can also be expressed as a function of tissue oxygen saturation, $\mathrm{S}_{\mathrm{t}} \mathrm{O}_{2}$ as follows:

$$
\mu_{\mathrm{a}}(\lambda)=\left(\left(\varepsilon_{\mathrm{HbO}_{2}}-\varepsilon_{\mathrm{Hb}}\right) \mathrm{S}_{\mathrm{t}} \mathrm{O}_{2}+\varepsilon_{\mathrm{Hb}}\right) T .
$$


Here, the total hemoglobin concentration, $T$, is given by the direct sum of $C_{\mathrm{HbO}_{2}}$ and $C_{\mathrm{Hb}}$, while $\mathrm{S}_{\mathrm{t}} \mathrm{O}_{2}$ is the ratio of $C_{\mathrm{HbO}_{2}}$ and $T$.

Based on the reflectance attenuation, this work used the fminsearch function in MATLAB to find the best estimation of $\mathrm{S}_{\mathrm{t}} \mathrm{O}_{2}$ and of other unknown parameters (i.e., $G_{0}, d_{0}, G_{1}, d_{1}$ and $T$ ) in Eq. (1). All these parameters were assigned with a random value of ' 1 ' at the beginning of the fitting process. The value of $\varepsilon_{\mathrm{HbO}_{2}}$ and $\varepsilon_{\mathrm{Hb}}$ of the chosen wavelengths was taken from Zijlstra. ${ }^{13}$ This fitting process ended when the number of iterations reached 1000 or when the computed absolute mean difference between the measured and calculated attenuation value in Eq. (1) was less than $10^{-20}$, whereby the optimum value of these parameters was assumed to have been found. An extensive discussion of the calculation of $\mathrm{S}_{\mathrm{t}} \mathrm{O}_{2}$ map based on the data cube obtained from the employed multispectral system is available in other work. ${ }^{14}$

\section{Results}

Table 1 shows the average mean and standard deviation of $\mathrm{S}_{\mathrm{t}} \mathrm{O}_{2}$ of control sites collected from the eight healthy volunteers recruited in this work. The average of these values in Table 1 for all skin sites is calculated as $50.1 \pm 1.53 \%$.

The wound image and its $\mathrm{S}_{\mathrm{t}} \mathrm{O}_{2}$ map for the three injured individuals are shown in Figs. 2-4 (a and b). The healing process of these wounds was suspected to be in the wound proliferation phase based on their physical appearance and wound age. These $\mathrm{S}_{\mathrm{t}} \mathrm{O}_{2}$ maps were averaged for a bin size of $20 \times 20$ pixels to reduce variability in the image. Also shown at the bottom of Figs. 2-4 is the $\mathrm{S}_{\mathrm{t}} \mathrm{O}_{2}$ profile across the selected $y$-axis in the $\mathrm{S}_{\mathrm{t}} \mathrm{O}_{2}$ mapping of the skin regions marked by the black dotted box. A brief description of these wounds is included in the figure caption. The mean and standard deviation of $\mathrm{S}_{\mathrm{t}} \mathrm{O}_{2}$

Table 1. Mean and standard deviation of transcutaneous blood oxygen saturation, $\mathrm{S}_{\mathrm{t}} \mathrm{O}_{2}$, of control skin sites.

\begin{tabular}{lc}
\hline Skin sites & $\begin{array}{r}\text { Mean } \begin{array}{r} \pm \text { standard deviation } \\
\text { of percent } \mathrm{S}_{\mathrm{t}} \mathrm{O}_{2}\end{array} \\
\hline \text { Central forehead }\end{array}$ \\
Posterior forearm & $48 \pm 1.16 \%$ \\
Proximal ankle & $50.1 \pm 1.54 \%$ \\
Thenar of palm & $54 \pm 2.94 \%$ \\
\hline
\end{tabular}
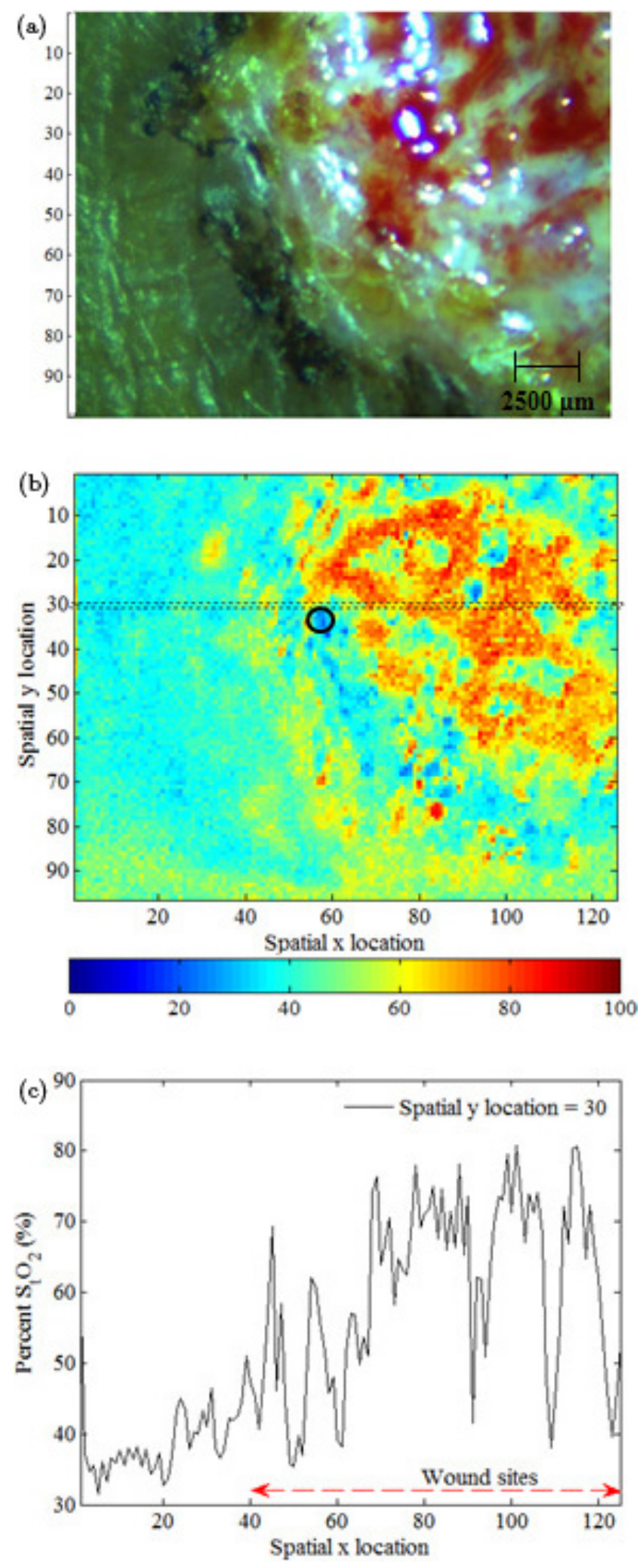

Fig. 2. (a) The subject is a 21-year-old male with a one-weekold wound on his lateral posterior forearm from a road accident. (b) The calculated $\mathrm{S}_{\mathrm{t}} \mathrm{O}_{2}$ map of the corresponding wound. Colorbar indicates the $\mathrm{S}_{\mathrm{t}} \mathrm{O}_{2}$ value. (c) The $\mathrm{S}_{\mathrm{t}} \mathrm{O}_{2}$ profile across spatial $y=30$ of the $\mathrm{S}_{\mathrm{t}} \mathrm{O}_{2}$ map. 
(a)
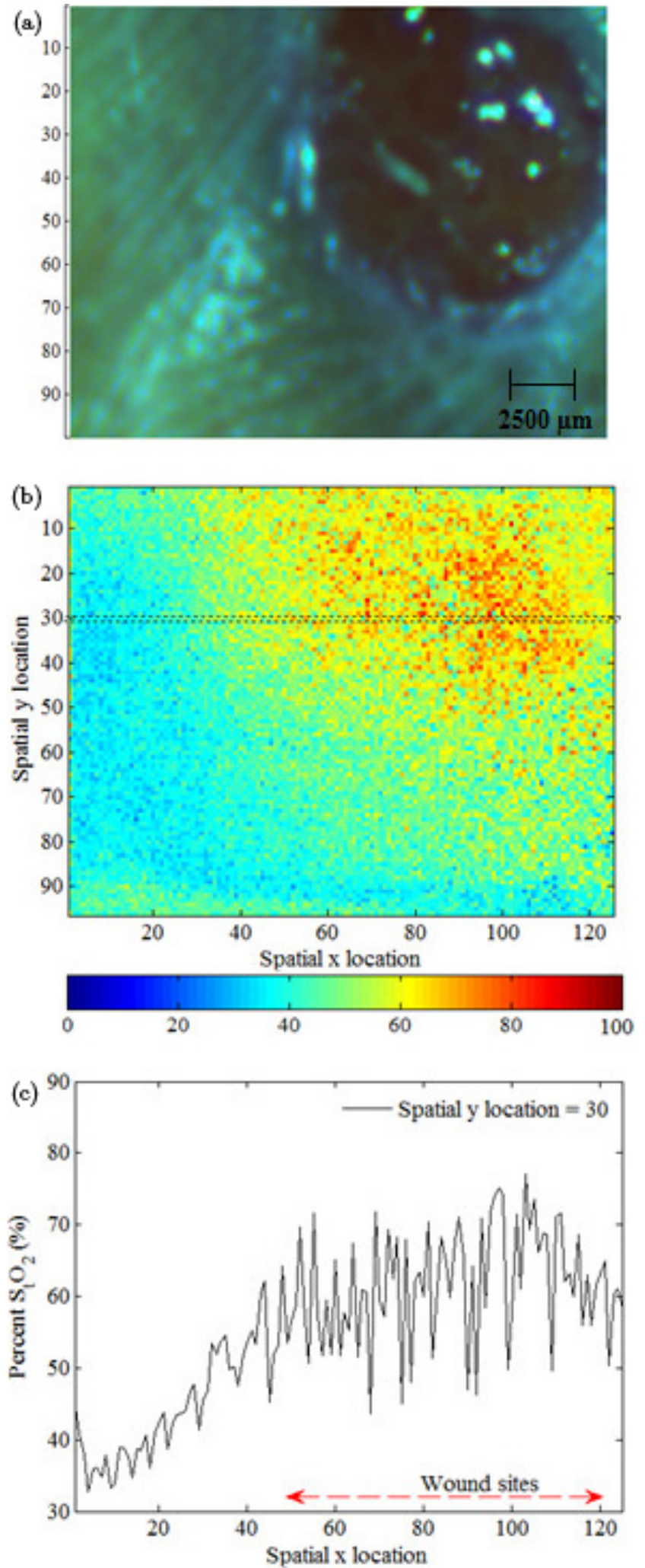

Fig. 3. (a) The subject is a 24-year-old nonsmoking female with a five-day-old blister wound on her central abdomen. (b) The calculated $\mathrm{S}_{\mathrm{t}} \mathrm{O}_{2}$ map of the corresponding wound. Colorbar indicates the $\mathrm{S}_{\mathrm{t}} \mathrm{O}_{2}$ value. (c) The $\mathrm{S}_{\mathrm{t}} \mathrm{O}_{2}$ profile across spatial $y=30$ of the $\mathrm{S}_{\mathrm{t}} \mathrm{O}_{2}$ map.
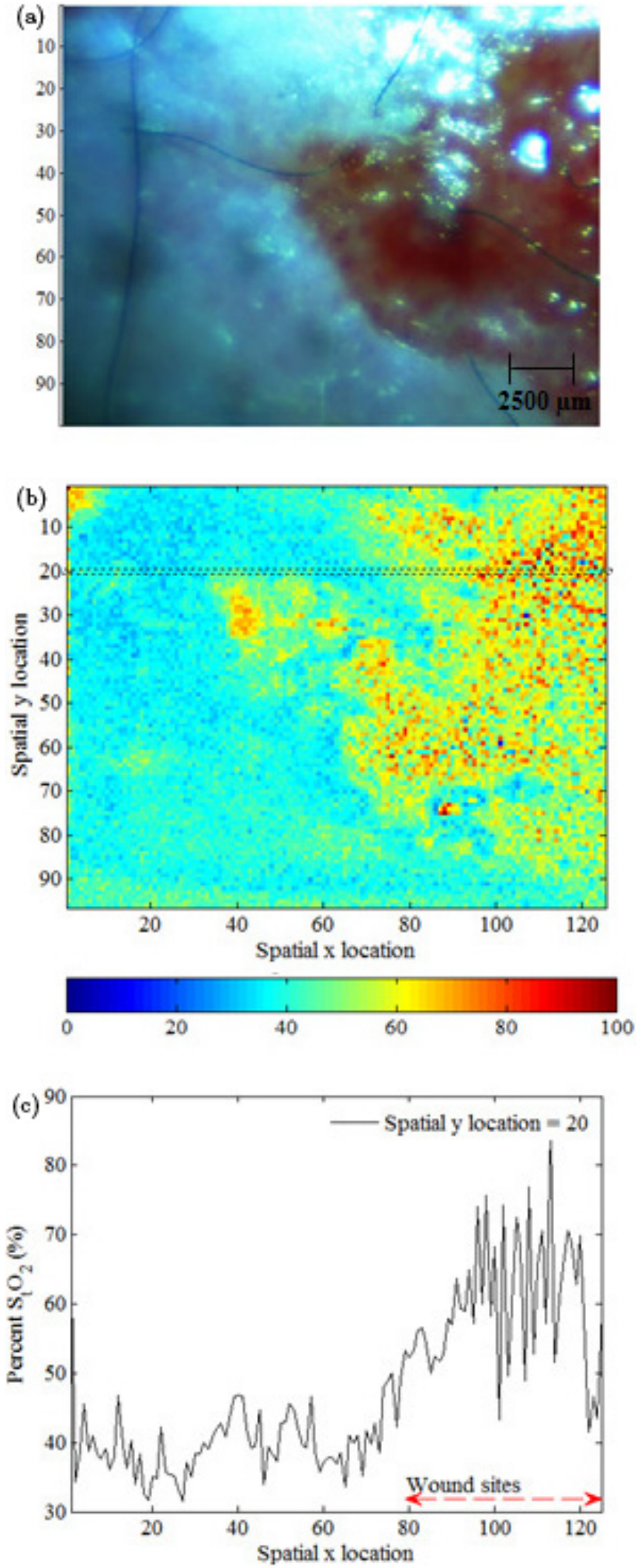

Fig. 4. (a) The subject is a 24-year-old nonsmoking male with a two-week-old second degree burn wound on the frontal part of his right foot. (b) The calculated $\mathrm{S}_{\mathrm{t}} \mathrm{O}_{2}$ map of the corresponding wound. Colorbar indicates the $\mathrm{S}_{\mathrm{t}} \mathrm{O}_{2}$ value. (c) The $\mathrm{S}_{\mathrm{t}} \mathrm{O}_{2}$ profile across spatial $y=20$ of the $\mathrm{S}_{\mathrm{t}} \mathrm{O}_{2}$ map. 
Table 2. Mean and standard deviation of transcutaneous blood oxygen saturation, $\mathrm{S}_{\mathrm{t}} \mathrm{O}_{2}$, of wound sites and its adjacent skins calculated for spatial $y$ location selected from $\mathrm{S}_{t} \mathrm{O}_{2}$ map in Figs. 2-4.

\begin{tabular}{lcc}
\hline & $\begin{array}{c}\text { Mean } \pm \text { standard deviation of } \\
\text { percent } \mathrm{S}_{\mathrm{t}} \mathrm{O}_{2}\end{array}$ \\
\cline { 2 - 3 } & $\begin{array}{c}\text { Unwounded } \\
\text { skin sites }\end{array}$ & Wound sites \\
\hline Wound location & $39.2 \pm 5.22 \%$ & $60.55 \pm 12.84 \%$ \\
\hline Lateral posterior forearm & $45.2 \pm 8.05 \%$ & $62.1 \pm 8.23 \%$ \\
Central abdomen & $40.36 \pm 5.33 \%$ & $60.04 \pm 9.8 \%$ \\
\hline
\end{tabular}

of the wound bed and the adjacent unwounded skin regions calculated from the $\mathrm{S}_{\mathrm{t}} \mathrm{O}_{2}$ profile are tabulated in Table 2.

The relationship between the mean $\mathrm{S}_{\mathrm{t}} \mathrm{O}_{2}$ of control sites listed in Table 1 and the unwounded skin sites in Table 2 was statistically determined using a two-tailed independent samples $t$-test in SPSS software (SPSS 22, Inc., Chicago, Illinois) with confidence level of $95 \%$. The same analysis was also performed on the oxygen saturation value calculated for the wounded and unwounded sites in Table 2. This statistic test revealed a significance value ( $\rho$ value) of 0.02 for the $\mathrm{S}_{\mathrm{t}} \mathrm{O}_{2}$ of control sites and unwounded skin region, while $\rho=0.005$ was obtained for the association test between $\mathrm{S}_{\mathrm{t}} \mathrm{O}_{2}$ of the wound and its surrounding tissues.

\section{Discussion}

The $\mathrm{S}_{\mathrm{t}} \mathrm{O}_{2}$ values for subjects suffering from acute wound of different wound ages shown in Figs. 2-4 (c) and Table 2 reveals an overall high average percent of $\mathrm{S}_{\mathrm{t}} \mathrm{O}_{2}$ of $61 \pm 10.3 \%$ at wound sites. This reading is considerably consistent regardless of the skin sites suggesting this as the most probable value for granulating tissues, and as being likely in the healing of wound bed, especially during the proliferation phase. Meanwhile, this study has observed a lower mean $\mathrm{S}_{\mathrm{t}} \mathrm{O}_{2}$ of $41.6 \pm 6.2 \%$ at skins adjacent to the wound, wherein based on Table 2 the mean $\mathrm{S}_{\mathrm{t}} \mathrm{O}_{2}$ of wounded sites is on average 1.5 times greater than that of its surrounding tissues. This value is also lower than that from the control skin sites, as shown in Table 1, with the calculated average $\mathrm{S}_{\mathrm{t}} \mathrm{O}_{2}$ given by $50.1 \pm 1.53 \%$. Based on the $t$-test analysis results, statistical significant was found in both the relationships between the estimated $\mathrm{S}_{\mathrm{t}} \mathrm{O}_{2}$ for the control and unwounded skin sites $(\rho=0.02)$, and that between the wounded and unwounded skin region $(\rho=0.005)$. These readings are agreeable as a high $\mathrm{S}_{\mathrm{t}} \mathrm{O}_{2}$, which results from an increase in blood perfusion to the wound bed, is compulsory for facilitating wound healing. Since most of the oxygen had been drawn to the wound sites, it deprived the surrounding tissue of oxygen. The decrease in $\mathrm{S}_{\mathrm{t}} \mathrm{O}_{2}$ of the surrounding tissues lower than that of the baseline value following injury was also observed in Zhang et al., ${ }^{7}$ this value returned to that similar to the normal skin site after day 7 . Interestingly, it was observed in this work that the $\mathrm{S}_{\mathrm{t}} \mathrm{O}_{2}$ value of the yellowish fibrin slough was significantly lower than that of the granulating tissues and the normal skin tissues. The fibrin slough consists mainly of dead subcutaneous tissues and can be noticeably traced by cool color in the $\mathrm{S}_{\mathrm{t}} \mathrm{O}_{2}$ map in Fig. 2. The result revealed a severe necrosis of the tissue with a value of approximately $10 \%$ at this corresponding site (an example of this is marked by a dark solid circle in Fig. 2(b)).

Table 2 shows a mean variability of $10.3 \%$ at the wound bed compared to $6.2 \%$ in the $\mathrm{S}_{\mathrm{t}} \mathrm{O}_{2}$ of the unwounded skin. Both of these values are higher than that of the $\mathrm{S}_{\mathrm{t}} \mathrm{O}_{2}$ collected from healthy control samples. The mean standard deviation of this value in Table 1 was calculated as $1.53 \%$. Even though the spatial and temporal fluctuation in this value has been observed in other related works, ${ }^{15}$ this variability can be minimized with the use of an integration time of $5 \mathrm{~s}$ of CCD during the data acquisition process. Besides, the averaging of $\mathrm{S}_{\mathrm{t}} \mathrm{O}_{2}$ map at a bin size of $20 \times 20$ pixels can also reduce spatial differences in the image. The observed oscillation in $\mathrm{S}_{\mathrm{t}} \mathrm{O}_{2}$ is, therefore, presumably originating from that of changes in the microvascular vasomotion activities. The increased variation in $\mathrm{S}_{\mathrm{t}} \mathrm{O}_{2}$ at wound sites together with their high $\mathrm{S}_{\mathrm{t}} \mathrm{O}_{2}$ could indicate a functioning arterial vasomotion system compared to their surroundings. This trend may signal whether the healing process of wounds such as skin grafts is taking place.

This study has demonstrated that the Extended Modified Lambert-Beer model is able to detect differences in $\mathrm{S}_{\mathrm{t}} \mathrm{O}_{2}$ for wound sites and their adjacent skin areas using a priori information on the absorption coefficients of hemoglobin components in the wavelength range of $520-600 \mathrm{~nm}$. This shows that, as a complementary to the light attenuation given in the Modified Lambert-Beer model, the total light 
attenuation of the dermis and epidermis layers may be further sufficiently broken down, with the former being loosely represented by the wavelength dependent exponential term in Eq. (1), while the melanin light absorption in the epidermis takes place via a linear wavelength dependent function. Unlike the previous works, ${ }^{7,16}$ the results in Figs. $2-4$ showed a comprehensive high resolution spatial information on the wound tissue oxygen saturation level, suggesting the employed system and strategy can be suitably used for the clinical evaluation of different types of wound.

\section{Conclusion}

This work adopted the multispectral imaging technique to investigate the $\mathrm{S}_{\mathrm{t}} \mathrm{O}_{2}$ percent of acute wound tissues, and compare the readings with those of their surrounding tissues and the tissues of control sites. This study concluded that an averagely high $\mathrm{S}_{\mathrm{t}} \mathrm{O}_{2}$ of approximately $60 \%$ at the granulating tissue, and $42 \%$ at its surrounding tissues is likely to ensure timely wound healing. The large fluctuation in $\mathrm{S}_{\mathrm{t}} \mathrm{O}_{2}$ values of around $11 \%$ in granulation skin sites should also be ensued; this is agreeable as the oscillating tone of the vasomotion activities also varies spatially. Another highlight of this study is the finding of a significantly low $\mathrm{S}_{\mathrm{t}} \mathrm{O}_{2}$ of $10 \%$ at the necrotic or fibrin tissues. This work has concluded that the recruited strategy can potentially be used for wound healing assessment in routine clinical application. The future work include determining the relationship between the microcirculation properties (tissues oxygenation and blood flow) and healing status of different types of wounds. The primary interest is to determine differences in these parameters for acute and chronic wounds, and changes in these values as wound healing progresses.

\section{Acknowledgment}

This research was supported in part by Ministry of Education Malaysia under grant no. FRGS 1581 and University Tun Hussein Onn Malaysia under grant no. U165.

\section{References}

1. J. Marotz, A. Siafliakis, A. Holmer, A. Kulcke, F. Siemers, "First results of a new hyperspectral camera system for chemical based wound analysis," Wound Med. 10-11, 17-22 (2015).
2. S. Enoch, D. J. Leaper, "Basic science of wound healing," Surgery (Oxford), 26, 31-37 (2008).

3. H. Wang, L. Shi, J. Qin, S. Yousefi, Y. Li, R. K. Wang, "Multimodal optical imaging can reveal changes in microcirculation and tissue oxygenation during skin wound healing," Lasers Surg. Med. 46, 470-478 (2014).

4. M. Frieri, K. Kumar, A. Boutin, "Wounds, burns, trauma, and injury," Wound Med. 13, 12-17 (2016).

5. W. K. Barnikol, H. Ptzschke, "A novel, non-invasive diagnostic clinical procedure for the determination of an oxygenation status of chronic lower leg ulcers using peri-ulceral transcutaneous oxygen partial pressure measurements: Results of its application in chronic venous insufficiency (CVI)," GMS German Med. Sci. 10, 1-22 (2012).

6. J. Q. Nguyen, C. Crouzet, T. Mai, K. Riola, D. Uchitel, L. H. Liaw, N. Bernal, A. Ponticorvo, B. Choi, A. J. Durkin, "Spatial frequency domain imaging of burn wounds in a preclinical model of graded burn severity," J. Biomed. Opt. 18, 066010066010 (2013).

7. S. Zhang, S. Gnyawali, J. Huang, W. Ren, G. Gordillo, C. K. Sen, R. Xu, "Multimodal imaging of cutaneous wound tissue," J. Biomed. Opt., 20, 016016 (2015).

8. M. Flanagan, "The physiology of wound healing," J. Wound Care 9, 299-300 (2000).

9. P. Ducommun, P. A. Ruffieux, M. P. Furter, I. Marison, U. von Stockar, "A new method for online measurement of the volumetric oxygen uptake rate in membrane aerated animal cell cultures," $J$. Biotechnol. 78, 139-147 (2000).

10. S. Schreml, R. J. Meier, O. S. Wolfbeis, T. Maisch, R. M. Szeimies, M. Landthaler, R. Johannes, S. Francesco, K. Ingo, P. Babilas, "2D luminescence imaging of physiological wound oxygenation," Exp Dermatol 20, 550-554 (2011).

11. A. Huong, X. Ngu, "The application of extended modified Lambert Beer model for measurement of blood carboxyhemoglobin and oxyhemoglobin saturation," J. Innov. Opt. Health Sci. 7, 145002 (2014).

12. A. Huong, X. Ngu, "In Situ Monitoring Of Mean Blood Oxygen Saturation Using Extended Modified Lambert Beer Model," Biomed. Eng. Appl. Basis Communi. 27, 1550004-15500010 (2015).

13. W. G. Zijlistra, A. Buursma, O. W. Van Assendelft, Visible and Near Infrared Absorption Spectra of Human and Animal Haemoglobin: Determination and Application, VSP Books (2000), pp. 180-194.

14. S. P. Philimon, A. Huong, X. Ngu, "Multispectral imaging system for quantitative assessment of transcutaneous blood oxygen saturation," J. Teknol. 77, 37-41 (2015). 
A. Huong, S. Philimon \& X. Ngu

15. A. K. C. Huong, S. P. Philimon, X. T. I. Ngu, Noninvasive monitoring of temporal variation in transcutaneous oxygen saturation for clinical assessment of skin microcirculatory activity, In Int. Conf. Innovation in Biomedical Engineering and Life Sciences, Springer (2015).
16. A. Basiri, M. Nabili, A. Libin, S. Groah, H. J. Noordmans, J. C. Ramella-Roman, "Use of a multispectral camera in the characterization of skin wounds," Opt. Express 18, 3244-3257 (2010). 